J. Lake Sci. (湖泊科学) , 2007, 19(5) :577 -584

http:// www. jlakes. org. E-mail: jlakes@ niglas. ac. cn

(c) 2007 by Journal of Lake Sciences

\title{
淹水对菖蒲萌发及幼苗生长的影响”
}

\author{
曹 旳 ${ }^{1,2}$, 王国祥 ${ }^{\text {*** }}$, 刘 玉 ${ }^{1}$
}

(1: 南京师范大学地理科学学院, 江苏省环境演变与生态建设重点实验室, 南京 210097)

( 2 : 江西师范大学地理与环境学院, 南昌 330022 )

摘 要: 应用盆栽试验方法, 研究了菖蒲在不同淹水深度下的萌发和幼苗生长. 试验共设 $20 、 40 、 60 、 80 、 100$ 和 $120 \mathrm{~cm}$ 等 6 个处理,处理时间为 $86 \mathrm{~d}$. 结果表明: (1) 不同淹水深度对菖蒲萌发和幼苗有不同程度的影响,在持续完全淹水条件下, 菖 蒲幼苗的萌发率仅为淹水 $20 \mathrm{~cm}$ 条件下的 $1 / 3$, 幼苗的平均高度为淹水 $20 \mathrm{~cm}$ 条件下的 $1 / 3$ 左右; (2) 菖蒲幼苗叶片长度、 宽度、叶片面积和基茎随淹水深度增加而减小, 叶片数量和叶片含水率随淹水深度增加而增大; (3) 在试验的 $27 \mathrm{~d} 、 54 \mathrm{~d}$ 、 $86 \mathrm{~d}$, 各淹水深度植物的根、茎、叶及总生物量都比淹水 $20 \mathrm{~cm}$ 有不同程度的降低, 并随淹水时间的延长, 各淹水深度条件 下的生物量差别增大. 在不同淹水深度条件下, 根、茎和叶生物量增量均表现为茎的最多, 叶的次之,根的最少; (4) 菖蒲 幼苗在水深为 $100-120 \mathrm{~cm}$ 的逆境条件下时, 叶片细胞膜脂过氧化加剧, 细胞质膜透性增加; (5) 菖蒲幼苗叶片的叶绿素 $\mathrm{a} 、 \mathrm{~b}$ 含量和类胡萝卜素 (Car) 含量随淹水深度的增加而下降; (6) Fv F F 、ETR、 $q P$ 随淹水深度的增加而下降, 长时间 (54$86 \mathrm{~d}$ ) 完全淹水 (水深 $100-120 \mathrm{~cm}$ ) 对菖蒲幼苗光合系统 PS II 有显著影响, 影响菖蒲幼苗 PS II 的非循环光合电子传递速 率, 天线色素吸收的光能用于光化学电子传递的份额减少, 参与 $\mathrm{CO}_{2}$ 固定的电子减少; $q N$ 在 $54 \mathrm{~d} 、 86 \mathrm{~d}$ 的都有不同程度的 增加,菖蒲叶片 PS II 系统没有遭到破坏.

关键词: 淹水; 菖蒲; 萌发; 幼苗生长; 叶绿素苂光参数

\section{Effects of flooding on germination and seedlings growth of Sweet Flag (Acorus calamus $\mathbf{L}$. )}

\section{CAO Yun ${ }^{1,2}$, WANG Guoxiang ${ }^{1} \&$ LIU Yu ${ }^{1}$}

(1:School of Geography Science, Nanjing Normal University; Jiangsu Key Laboratory of Environmental Change and Ecological Construction, Nanjing 210097,P. R. China)

(2:College of Geography and Environment, Jiangxi Normal University, Nanchang 330023,P. R. China)

Abstract: Germination and seedlings growth of Sweet Flag under submerged conditions of water depth of 20, 40, $60,80,100,120 \mathrm{~cm}$ were researched by the way of pot culture experiment lasted 86 days. The results were as follows: (1) Different water depths had different effects on germination and seedlings growth of Sweet Flag. Germination ratio and average seedlings height in complete flooding condition were just one third of that in depth of $20 \mathrm{~cm}$ condition; (2) Height and width of seedlings leaves, leaf area and diameter of rhizome reduced while quantity of leaf and leaf water content increased with increase of water depth; (3) Biomass of root, rhizome and leaf and total biomass of every treatment reduced in different measures compared with water depth of $20 \mathrm{~cm}$ on the 27th, 54th and 86th days. With time increase, biomass differences under different water depths. Biomass of rhizome increased most, leaf lay the second place and root increased least under different water depths. (4) The cell membrane lipid peroxidation and permeability of the seedlings leaves increased in the adversity of water depth from 100 to $120 \mathrm{~cm}$; (5) Chlorophyll- $a$, Chlorophyll-b and Carotenoid of seedlings leaves reduced with increase of water depth; (6) As water depth increased, $F v / F m$ and $q P$ reduced. Under the condition of Long-term (54-58d) complete flooding

* 教育部科技创新工程重大项目培育基金(705824)、江苏省重点科技专项 (BM2002701)、国家高技术研究发展计划 (863) 资助项目 (2003AA601100) 联合资助. 2006-09-15 收稿;2006-12-18 收修改稿. 曹昀, 男, 1974 年生, 博 士,副教授;E-mail : . yun. cao@163.com.

** 通讯作者;E-mail: wangguoxiang@ njnu. edu.cn. 
$(100-120 \mathrm{~cm})$, PSII of the seedlings had been significantly effected. ETR was affected. The portion of light energy absorbed by antenna pigment which was used for actinic chemistry electron transfer decreased. Electron taken part in $\mathrm{CO}_{2}$ fixation decreased. $q N$ increased in different measures on the 54th and 86th days. PS II of Sweet Flag leaf didnt be destroyed.

Keywords: Flooding; Sweet Flag; germination; seedlings growth; chlorophyll fluorescence

湖泊、河流和水库消落区指的是季节性水位涨落而使周边被淹没土地周期性地出露于水面的一段特殊 区域, 是水生生态系统和陆生生态系统能量、物质输移与转化的活跃地带 ${ }^{[1]}$. 消落区的植被由于不适应水 生生境而消亡, 生态系统结构和功能简单化,生态系统稳定性降低, 脆弱性增强; 水土流失加剧, 岸边污染加 重. 消落区环境敏感性强、波动频率大、适应范围窄且容易发展灾变,在人类不合理的干扰下,如消落区不 合理的开发利用,极易消弱消落区的生态服务功能,甚至引发环境灾难. 因此对消落区进行生态修复,重建 健康稳定的湿地生态系统才可以解决上述问题. 其中从自然界篎选耐淹植物在水间带种植、增加植物生物 量、减少淤积是迫在眉睫的问题.

Loucks ${ }^{[2]}$ 提出在水位容易出现波动的地区 (如水库、河岸、堤岸等湿地) 种植耐淹植物可减少水土流失 从而保护湿地. 研究菖蒲在不同水位条件下的幼苗生长、生物量、叶绿素含量和叶绿素苂光特性及其淹水 逆境的适应能力与其相应的结构和生理特征, 可以为湖泊、河流和水库消落区植物生态对策和群落的物种 组成研究、湿地恢复中的植物选种提供一定的理论依据.

\section{1 材料与方法}

试验在南京师范大学仙林校区江苏省环境工程重点实验室“水环境生态修复中试平台”台阶式实验水 槽进行. 2006 年 2 月从南京市仙林大学城九乡河湿地采集野生的菖蒲根状茎, 切成 $2-3 \mathrm{~cm}$ 的小段 ${ }^{[3]}$, 栽 培到 $25 \mathrm{~cm}$ 深的塑料盆(每盆 30 小段) 中试验 (土壤基质为沙壤土). 设置 6 个水深处理: $\mathrm{C}_{20}(20 \mathrm{~cm}), \mathrm{C}_{40}$ $(40 \mathrm{~cm}) 、 \mathrm{C}_{60}(60 \mathrm{~cm}) 、 \mathrm{C}_{80}(80 \mathrm{~cm}) 、 \mathrm{C}_{100}(100 \mathrm{~cm})$ 和 $\mathrm{C}_{120}(120 \mathrm{~cm})$,3 次重复. 将上述植物连同塑料盆放置在 相应的水深进行试验.

\section{1 环境因子测定}

$\mathrm{TN} 、 \mathrm{NH}_{4}^{+}-\mathrm{N} 、 \mathrm{NO}_{2}^{-}-\mathrm{N} 、 \mathrm{NO}_{3}^{-}-\mathrm{N} 、 \mathrm{TP}$ 用 Skalar 水质流动分析仪测定, $\mathrm{COD}_{\mathrm{Mn}}$ 采用高锰酸钾氧化法测定, 使用 光照计测定不同水深的光照强度; 用溶解氧仪测定相应水深的水温和 DO 等; 不同淹水深度土壤的 Eh 值是 用 FJA - 15 型氧化还原电位测定仪在白金电极插人到土层中部,待 $\mathrm{Eh}$ 值稳定后时读取.

\section{2 形态学指标测定}

每周统计测量菖蒲的萌发率、幼苗的高度、茎径、叶片数、叶片的长宽,各指标求平均值后比较. 在试验 的 $27 \mathrm{~d}, 54 \mathrm{~d}, 86 \mathrm{~d}$ 每组收割 5 株, 分开叶、根状茎和根, 称量, 求平均值为生物量.

叶片含水率采用烘干称重法, 各组随机选取 5 片菖蒲幼苗叶片, 测定样品叶片的鲜重, $80^{\circ} \mathrm{C}$ 烘至恒重后 再称干重,计算叶片的含水率: 含水率 $(\%)=$ (鲜重 - 干重 $) /$ 鲜重 $\times 100 \%$.

\section{3 叶片色素测定}

叶绿素和类胡萝卜素含量的测定, 采用 Arnon 法 $^{[4]}$, 细胞膜透性用电导仪法 ${ }^{[5]}$ 测定.

\section{4 叶绿素荧光参数的测定}

早晨 8 点,连体叶片经暗适应 $5 \mathrm{~min}$ 后, 用饱和脉冲叶绿素菼光仪 Diving Pam(德国 Walz 公司) 和数据 采集软件 Wincontrol 进行测定, 测定温度为 $30^{\circ} \mathrm{C}$, 光化光强度设定为 2 , 饱和光强度为 6 , 测定苂光动力学参 数, 按下式计算: PS II 最大量子产量为 $F v / F m$; 光化学淬灭系数 $q P=\left(F m^{\prime}-F t\right) /\left(F m^{\prime}-F o\right)$; 非光化学淬灭 系数 $q N=\left(F m-F m^{\prime}\right) /(F m-F o)$; 相对光合电子传递速率 $E T R=Y i e l d \times P A R \times 0.84 \times 0.5$.

\section{5 菖蒲叶片的快速光响应曲线}

用 Diving Pam(德国 Walz 公司) 测定菖蒲叶片的光响应曲线. 初始光照强度为 2 , 饱和光强度为 6 , 时间 间隔为 $10 \mathrm{~s}$,测得不同光照强度下的快速光响应曲线. 


\section{2 结果与分析}

\section{1 试验水槽环境因子}

在试验期间,试验水体平均 $\mathrm{TN} 、 \mathrm{NH}_{4}^{+}-\mathrm{N} 、 \mathrm{NO}_{2}^{-}-\mathrm{N} 、 \mathrm{NO}_{3}^{-}-\mathrm{N} 、 \mathrm{TP}$ 和 $\mathrm{COD}_{\mathrm{Mn}}$ 的含量如表 1 .

表 1 试验期间平均水质情况

Tab. 1 Average water quality during the experimental period

\begin{tabular}{ccccccc}
\hline 测定指标 & $\mathrm{TN}$ & $\mathrm{TP}$ & $\mathrm{NH}_{4}^{+}-\mathrm{N}$ & $\mathrm{NO}_{2}^{-}-\mathrm{N}$ & $\mathrm{NO}_{3}^{-}-\mathrm{N}$ & $\mathrm{COD}_{\mathrm{Mn}}$ \\
\hline 数值 $(\mathrm{mg} / \mathrm{L})$ & 0.649 & 0.041 & 0.238 & 0.012 & 0.123 & 4.684 \\
\hline
\end{tabular}

试验水体各组的光照强度和溶解氧 ( DO) 如表 2 , 光照强度和溶解氧都随水深的增加而减少, 其中 $\mathrm{C}_{120}$ 的光照强度仅为 $\mathrm{C}_{20}$ 的 $1 / 3$ 左右. 与非淹水土壤相比, 淹水土壤的 $\mathrm{Eh}$ 值明显降低 $(P<0.01)$, 且随着淹水深 度的增加 $\mathrm{Eh}$ 值降低的幅度增大. 非淹水土壤的 $\mathrm{Eh}$ 值无论在何种温度条件下, 自始至终总是在 $470 \mathrm{mV}$ 左 右轻微变动.

表 2 试验期间光强、溶解氧和氧化还原电位

Tab. 2 Average light, DO and Eh during the experimental period

\begin{tabular}{ccccccc}
\hline 试验组 & $\mathrm{C}_{20}$ & $\mathrm{C}_{40}$ & $\mathrm{C}_{60}$ & $\mathrm{C}_{80}$ & $\mathrm{C}_{100}$ & $\mathrm{C}_{120}$ \\
光照强度 $(\mathrm{klx})$ & 29.0 & 24.0 & 20.0 & 17.0 & 13.0 & 10.0 \\
溶解氧 $(\mathrm{mg} / \mathrm{L})$ & 7.03 & 7.11 & 6.88 & 6.63 & 6.04 & 5.37 \\
$\mathrm{Eh}(\mathrm{mV})$ & 245 & 181 & 133 & 110 & 104 & 72 \\
\hline
\end{tabular}

\section{2 菖蒲的萌发与幼苗的初期生长}

菖蒲在各淹水条件下试验 $16 \mathrm{~d}$ 萌发率出现明显差别, 萌发率随淹水深度增加而降低,其中 $\mathrm{C}_{20}(54 \%)$ 与 $\mathrm{C}_{120}(29 \%)$ 有显著差异. 试验的 $17-86 \mathrm{~d}$, 各组的萌发率都有不同程度的增加, 第 $86 \mathrm{~d}, \mathrm{C}_{20}$ 的萌发率为 $98 \%$, 与 $\mathrm{C}_{100}(60 \%)$ 有显著差异, 与 $\mathrm{C}_{120}(35 \%)$ 存在着显著差异 $(P<0.01)$ (图 1). 试验前 $30 \mathrm{~d}$, 试验各组菖 蒲幼苗的平均高度差异不显著. 试验 $86 \mathrm{~d}$, 菖蒲幼苗的平均高度随淹水深度增加而降低, 但差异不显著. $\mathrm{C}_{20}$ 的幼苗平均高度为 $78.0 \mathrm{~cm} 、 \mathrm{C}_{120}$ 幼苗平均高度为 $57.6 \mathrm{~cm}$ (图 2). 可见淹水条件影响了菖蒲根状茎的萌 发率, 菖蒲在淹水深度小于 $80 \mathrm{~cm}$ 时最终萌发率可达 $73 \%$, 且生长良好; 菖蒲在淹水深度 $120 \mathrm{~cm}$ 时最终萌 发率仅为 $35 \%$, 但萌发后植株的平均高度与其他各组差异不大. 由于菖蒲的自然生境主要位于水边潮湿区 域, 淹水对其萌发和生长都会造成一定的影响, 在持续淹水 $120 \mathrm{~cm}$ 条件下, 菖蒲幼苗的萌发率约为淹水 20 $\mathrm{cm}$ 条件下的 $1 / 3$, 但幼苗的平均高度为淹水 $20 \mathrm{~cm}$ 条件下的 $3 / 4$ 左右.

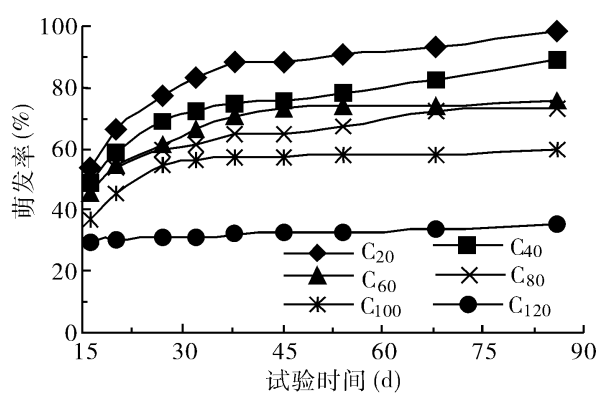

图 1 菖蒲幼苗的萌发率

Fig. 1 Germination ratio of sweet flag

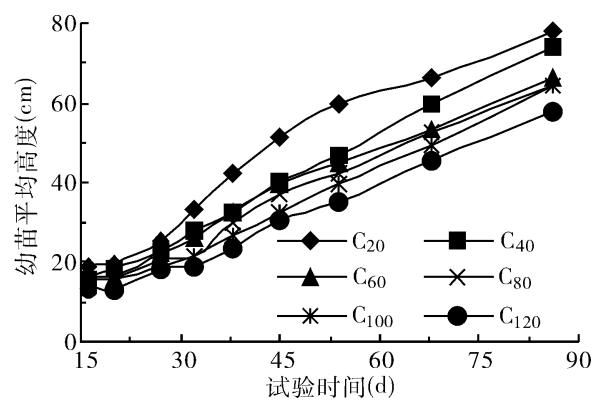

图 2 菖蒲幼苗的生长

Fig. 2 Growth of sweet flag's seedlings 


\section{3 菖蒲茎、叶的特征}

菖蒲幼苗叶片长度、宽度和基茎直径随淹水深度增加而减小, 叶片面积也随淹水深度增加而减小, 其中 叶面积下降极为明显, 叶片宽度、数量与基茎减小明显. 而叶片数量和叶片含水率随淹水深度增加而增大. $\mathrm{C}_{20}$ 和 $\mathrm{C}_{40}$ 的叶片大部分暴露在空气中, 而其他各组的叶片 $\mathrm{C}_{80} 、 \mathrm{C}_{100}$ 和 $\mathrm{C}_{120}$ 的叶片完全淹没在水中, 所以叶片 水分含量存在差异 (图 3 ).
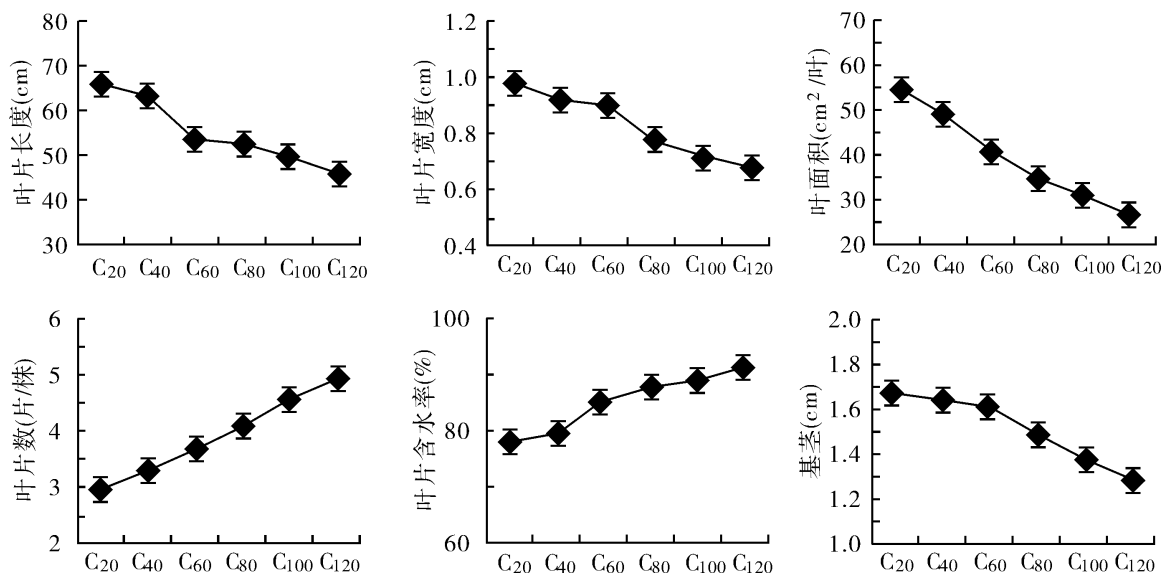

图 3 菖蒲茎、叶的特征变化

Fig. 3 Variation of stem and leaf of sweet flag's seedlings

\section{4 生物量动态变化}

2.4.1 生物量估算模型 植株收获后, 获得准确的生物量, 结合收获时测得的叶片形态学参数, 进行相关性 分析,结果发现叶片生物量与基茎半径 $\times$ 基茎半径 $\times$ 植株高度有较强的线形关系, 茎和根的生物量与其长 度有较强的线形关系. 在实验中采用基茎半径 $\times$ 基茎半径 $\times$ 植株高度这个参数估计菖蒲叶片生物量,根据 茎和根长度估算茎和根的生物量是可行的,结合实验过程中测定的根、茎、叶形态学参数,利用拟合方程,可 以估算出菖蒲在生长周期中的生物量变化 (图 4).

2.4 .2 生物量动态变化 在试验的 $27 \mathrm{~d} 、 54 \mathrm{~d} 、 86 \mathrm{~d}$, 各试验组的根、茎、叶及总生物量都比对照组 ( CK) 有不 同程度的降低,并随试验时间的延长,各淹水深度条件下的生物量差别增大. 在不同淹水条件下, 根、茎和 叶生物量增量均表现为茎的最多, 叶的次之, 根的最少, 叶茎根生物量分配平均为 1:1.59:0.82. $\mathrm{C}_{20}$ 在 $27 \mathrm{~d}$ 、 $54 \mathrm{~d} 、 86 \mathrm{~d}$ 的总生物量为 $2.54 、 9.24$ 和 $17.94 \mathrm{~g}$ /株 (干重), 分别为 $\mathrm{C}_{120}$ 的 $1.28 、 2.49$ 、和 2.13 倍, 二者存在显 著性差异 $(P<0.05)$. 同时 $\mathrm{C}_{20}$ 的根、茎、叶及总生物量也明显高于 $\mathrm{C}_{80}$ 和 $\mathrm{C}_{100}$ (图 5 ). 菖蒲的生境主要位于 池塘、湖泊岸边浅水处, 属于挺出水面生长的植物, $80 \mathrm{~cm}$ 以下的完全淹水环境导致水下光照不足, 氧气和 $\mathrm{CO}_{2}$ 浓度降低, 其生物量的积累明显减少. 只有在浅水环境 (淹水 $20 \mathrm{~cm}$ )下菖蒲的生物量积累最高, 淹水深 度再有增加 $\left(\mathrm{C}_{40} 、 \mathrm{C}_{60}\right)$, 其生物量的积累就会降低. 这主要是在淹水条件下, 菖蒲幼苗的光合作用和呼吸作 用受到抑制, 各器官的生长发育都受到限制, 叶面积减小, 造成植物生物量的减少(图 5 ).

\section{5 叶绿素含量}

在试验的 $27 \mathrm{~d} 、 54 \mathrm{~d} 、 86 \mathrm{~d}$, 菖蒲幼苗叶片的叶绿素 $a 、 b$ 含量随淹水深度的增加而下降. 在试验的 $27 \mathrm{~d}$ 叶 绿素 $a 、 b$ 含量各组之间差异性不显著,但 $\mathrm{C}_{20}$ 与 $\mathrm{C}_{120}$ 之间的 Car 含量差异显著. 在试验的 $54-86 \mathrm{~d}$, 各组内叶 绿素含量变化不大, 叶绿素 $a$ 含量在 $\mathrm{C}_{20}-\mathrm{C}_{80}$ 有稍微上升, 但 $\mathrm{C}_{100}$ 和 $\mathrm{C}_{120}$ 稍微下降; 叶绿素 $b$ 含量在 $\mathrm{C}_{20}-$ $\mathrm{C}_{100}$ 有稍微上升, 但 $\mathrm{C}_{120}$ 稍微下降. 这主要是随淹水时间的延长, 使各种细胞器, 特别是叶绿体和线粒体受 到伤害所致 ${ }^{[6]}$. 植物可以通过形态调节和减少色素含量来减少叶片对光能的捕获. 完全淹水会影响叶绿 素的生物合成,促进已合成的叶绿素分解,使其含量下降(图 6a、b).

类胡夢卜素 (Car) 含量随淹水深度的增加而下降, 在试验的 $54-86 \mathrm{~d}$, 类胡夢卜素含量 $\mathrm{C}_{60}-\mathrm{C}_{100}$ 有稍微 


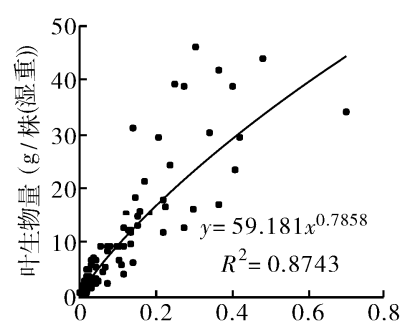

基茎半径 $\times$ 基茎半径 $\times$ 植株

高度

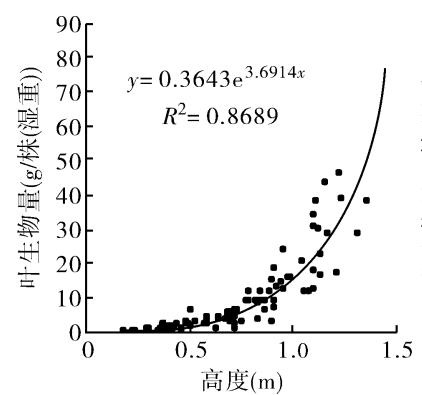

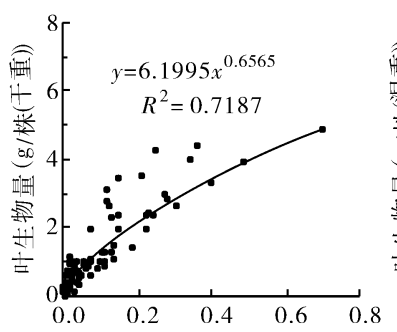

基茎半径 $\times$ 基茎半径 $\times$ 植株

高度

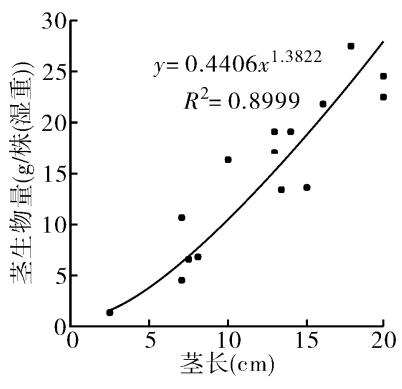

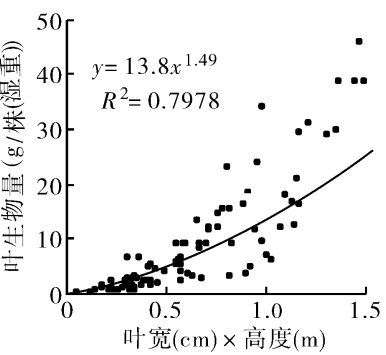

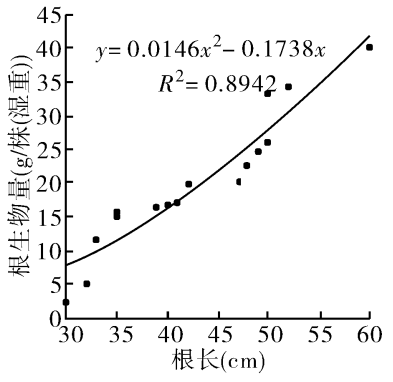

图 4 菖蒲幼苗的生物量与形态学特征的线形相关

Fig. 4 Linear correlation between biomass per plant of sweet flag's seedlings and the morphological characters

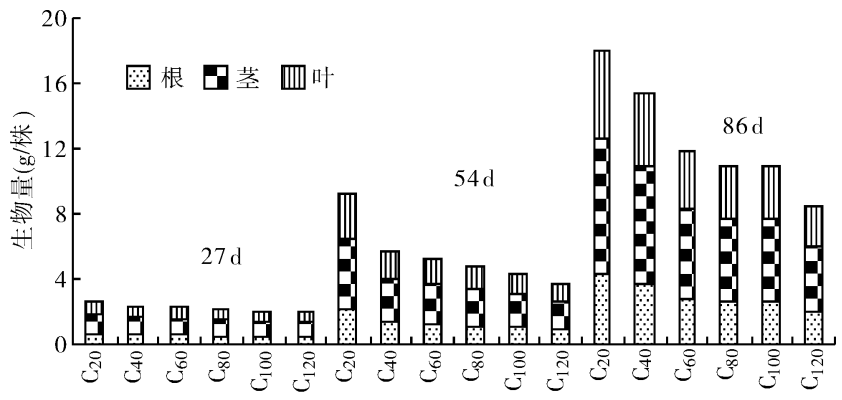

图 5 菖蒲幼苗的生物量

Fig. 5 The biomass of sweet flag's seedings

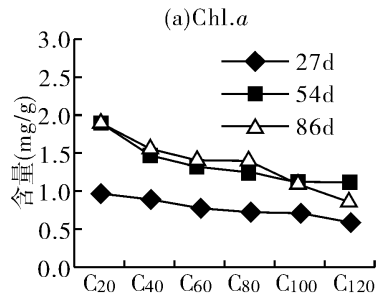

(b)Chl.b

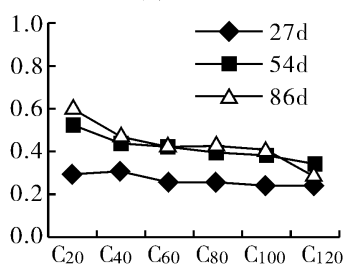

(c) Car

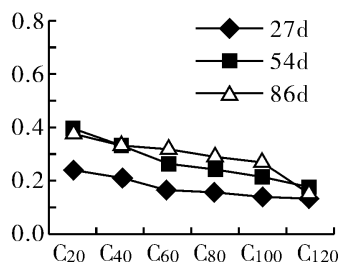

图 6 菖蒲幼苗叶片光合色素的变化

Fig. 6 Photo synthetic pigments contents of sweet flag's seedlings

上升, 其他各组无明显变化. 类胡夢卜素既是光合色素, 又是内源抗氧化剂, 它可以耗散过剩光能,清除活 性氧, 从而防止膜脂过氧化, 保护光合机构 ${ }^{[7]}$. 类胡萝卜素反映植物光能吸收和光保护的关系, 其值高低与 植物耐受逆境的能力有关, 随淹水深度的增加和时间的延长, 叶片的光合色素遭到破坏, 类胡夢卜素含量下 
降, 由于类胡萝卜素的稳定性较高, 其在光合色素中的比例相对稳定, 类胡萝卜素含量稳定有利于保护光合 机构,防止叶绿素的光氧化破坏( 图 6c).

\section{6 叶片细胞质膜透性}

菖蒲幼苗叶片细胞质膜透性 $(R P P)$ 随淹水深度的增加而升高, 在水深为 $20 \mathrm{~cm} 、 40 \mathrm{~cm} 、 60 \mathrm{~cm}$ 时的差别 不大, 在水深 $80 \mathrm{~cm}$ 开始上升, 水深 $120 \mathrm{~cm}$ 时, 菖蒲幼苗的细胞质膜透性为 $29.3 \%$, 明显高于其他各组 (图 7). 自由基伤害学说认为: 当植物处于逆境的条件下,植物细胞内活性氧的产生和清除的平衡受到破坏, 自 由基增加,引发和加剧细胞膜脂过氧化 ${ }^{[8]}$, 菖蒲幼苗在水深为 $100-120 \mathrm{~cm}$ 的逆境条件下时, 叶片细胞膜脂 过氧化加剧, 细胞质膜透性增加.

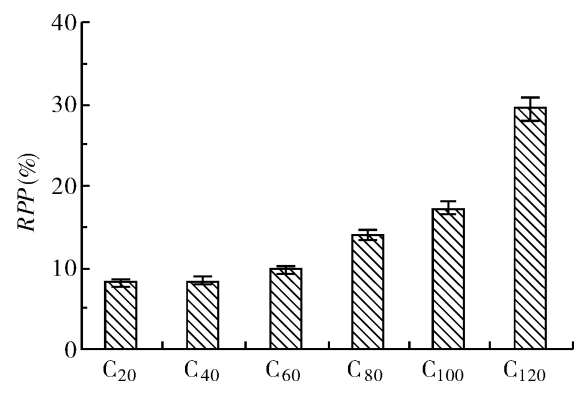

图 7 菖蒲叶片的细胞质膜透性

Fig. 7 Membrane permeability reed seedlings

\section{7 叶绿素荧光参数}

2.7.1 菖蒲幼苗的 $F v / F m 、 E T R 、 q P$ 和 $q N$ 比较 菖蒲在长期 淹水环境下, 当光能吸收量超过了光化学反应的利用量, 且 过剩的光能量得不到耗散时, 就会引起光合机构的破坏, 其 原初损伤部位在 PS II 上. 叶绿素菼光参数是评估 PS II 状态 良好的指标, 光系统 II (PS II ) 的光化学效率是表明光化学反 应状况的一个重要参数. 叶片叶绿素苂光与光合作用中各种 反应过程密切相关, 任何环境因子对光合作用的影响都可通 过叶片叶绿素若光动力学反映出来 ${ }^{[9]}$.

$F v / F m$ 是 PS II 最大光化学量子产量, 反映 PS II 反应中 心内禀光能转换效率或称最大 PS II 的光能转换效率. 非胁 迫条件下该参数的变化极小, 胁迫条件下该参数明显下降. 在逆境下, 当光能吸收量超过了光化学反应的 利用量, 且过剩的光能量得不到耗散时, 就会引起光合系统的破坏, 其原初损伤部位在 PS II 上. 菖蒲的 PS II 最大量子产量反映了当所有的 PS II 反应中心均处于开放态时的量子产量. 在试验的 $27 \mathrm{~d} 、 54 \mathrm{~d} 、 86 \mathrm{~d}, \mathrm{C}_{20}$ 的 $F v / F m$ 平均值约高于其他各试验组, 随着幼苗生长, 深水位的幼苗可以得到更好的光照, 这种差别逐渐 减小. 经方差分析, $\mathrm{C}_{20}$ 与对照 $\mathrm{C}_{100} 、 \mathrm{C}_{120}$ 的 $F v / F m$ 值存在显著差异 $(P<0.05)$. 表明完全长时间淹水对菖蒲 幼苗光合系统 PS II 的有显著影响 (图 8a).

(a) $F v / F m$

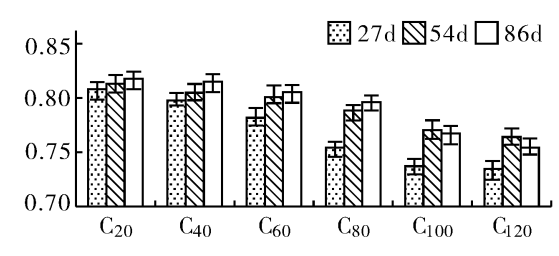

(c) $q P$

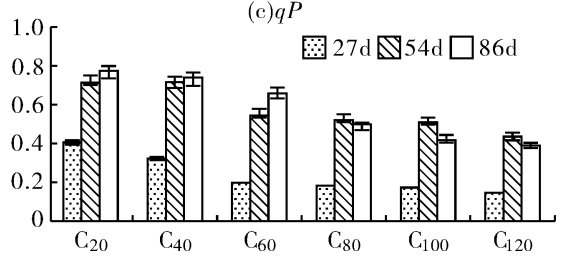

(b)ETR

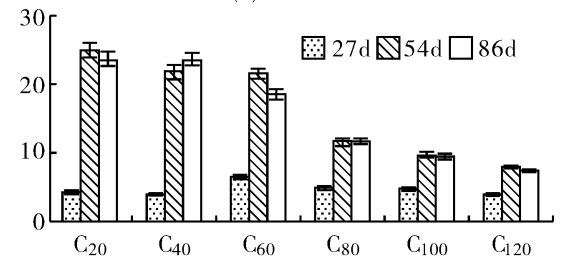

(d) $q N$

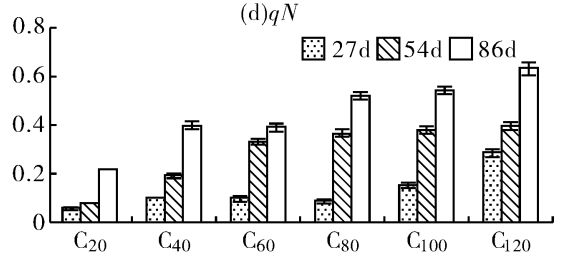

图 8 菖蒲幼苗的 $F v / F m 、 E T R 、 q P 、 q N$ 比较

Fig. $8 \mathrm{Fv} / \mathrm{Fm}, E T R, q P$ and $q N$ of sweet flag's seedlings

PS II 的非循环光合电子传递速率 (ETR) 是反映实际光强下的表观电子传递效率. ETR 用于度量光化 学反应导致碳固定的电子传递情况, 其值由光强、叶片吸收光系数和有效菼光产量计算得到 ${ }^{[10]}$. 试验 $27 \mathrm{~d}$, 各淹水条件下 ETR 值无显著差异; $54 \mathrm{~d}$ 和 $86 \mathrm{~d}, \mathrm{C}_{20}-\mathrm{C}_{60}$ 的 ETR 值有明显上升, 而 $\mathrm{C}_{80}-\mathrm{C}_{120}$ 的 ETR 值则上升 
缓慢. 经方差分析, $\mathrm{C}_{20}-\mathrm{C}_{60}$ 的 ETR 值与 $\mathrm{C}_{80}-\mathrm{C}_{120}$ 的 ETR 值有显著差异, 可见完全淹水影响到菖蒲幼苗 PS II 的非循环光合电子传递速率 (图 $8 \mathrm{~b}$ ).

光化学菼光淬灭系数 $q P$ 是 PS II 天线色素吸收的光能用于光化学电子传递的份额, 较低的 $q P$ 反映 PS II 中开放的反应中心比例和参与 $\mathrm{CO}_{2}$ 固定的电子减少. $q P$ 随淹水深度的增加和淹水时间的延长而减小. 试验 $27 \mathrm{~d}$, 各组菖蒲幼苗的 $q P$ 无显著差异; 试验 $54 \mathrm{~d}$ 和 $86 \mathrm{~d}, \mathrm{C}_{80}-\mathrm{C}_{120}$ 的 $q P$ 明显低于其他各组. 说明菖蒲 幼苗在完全淹水条件下, 天线色素吸收的光能用于光化学电子传递的份额减少, 参与 $\mathrm{CO}_{2}$ 固定的电子减少 (图 8c).

非光化学淬灭系数 $q N$ 反映的是天线色素吸收的光能不能用于电子传递而以热的形式耗散掉的光能部 分, 而热耗散是植物保护 PS II 的重要机制. $q N$ 随淹水深度的增加和淹水时间的延长而增加. 试验 $27 \mathrm{~d}$, 各 组菖蒲幼苗的 $q N$ 无显著差异; 试验 $54 \mathrm{~d}$ 和 $86 \mathrm{~d}, \mathrm{C}_{20}$ 的 $q N$ 明显低于其他组的菖蒲幼苗. 菖蒲幼苗随淹水时 间的延长, 以热的形式耗散掉的光能部分增加, 有效保护了菖蒲叶片 PS II 系统, 在试验的 $86 \mathrm{~d}$, 菖蒲叶片 PS II 系统没有遭到破坏 (图 $8 \mathrm{~d}$ ).

2.7.2 叶片的快速光响应曲线 淹水对菖蒲幼苗叶片光合作用的影响还体现在叶片对光的响应能力上. 在 光响应曲线中, 刚开始几分钟光照时间内的曲线变化具有重要的决定意义 ${ }^{[11]}$. 快速光响应曲线 (RLC) 为 电子传递速率随光强的变化曲线, 测定快速光响应曲线以确定菖蒲叶片的实际光化学效率.

$\mathrm{C}_{120}$ 的最小饱和光强为 $176 \mu \mathrm{mol} /\left(\mathrm{m}^{2} \cdot \mathrm{s}\right)$ 之外, 试验其他各组菖蒲幼苗的最小饱和光强皆位于 $505-$ $684 \mu \mathrm{mol} /\left(\mathrm{m}^{2} \cdot \mathrm{s}\right)$, 最大 ETR 则出现差异; $\mathrm{C}_{20}$ 的最大 $E T R$ 为 $25.1 \mu \mathrm{mol} /\left(\mathrm{m}^{2} \cdot \mathrm{s}\right)$, 显著高于 $\mathrm{C}_{120} E T R$ 的 $105 \%\left(7.7 \mu \mathrm{mol} /\left(\mathrm{m}^{2} \cdot \mathrm{s}\right)\right)($ 图 9$)$.

在 $100 \mu \mathrm{mol} /\left(\mathrm{m}^{2} \cdot \mathrm{s}\right)$ 的低光强下, 各组快速光响应曲线之间无明显的差异. 但随着光照强度的升高, $\mathrm{C}_{20}-\mathrm{C}_{60}$ 的有效电子传递速率逐渐大于 $\mathrm{C}_{80}-\mathrm{C}_{120}$. 在 $\mathrm{C}_{20}-\mathrm{C}_{60}$ 中, 菖蒲植株的有效电子传递速率无明显的 差异. 表明完全淹水对菖蒲植株的光响应曲线具有较大的影响, 这种影响主要体现在随淹水深度的增加, 可利用光照强度减少对植株的影响加剧.

\section{3 结论}

水位消落区是湖泊、河流和水库周边陆地生态系统和 水体生态系统的过渡地带, 其生态恢复与重建对湖泊、河 流和水库生态系统的结构和功能完善具有重要的意义. 因 此研究植物在对不同淹水条件下的萌发与生长特性和篎 选耐淹植物物种, 可为湖泊、河流和水库的水位消落区的 生态系统保育和植被恢复提供参考数据.

$\mathrm{Hook}^{[12]}$ 等人认为, 在淹水条件下, 氧气供应减少, 加 速了厌氧呼吸, 乙醇、乙醛等对植物有害物不断积累, 从而 导致不耐淹植物产生淹水伤害, 而耐淹植物可通过形态和 生理的变化来适应淹水环境. 菖蒲对淹水环境的适应主要 是决定其自身的生理生化活动的特性和组织结构特点. 菖 蒲在淹水深度 $120 \mathrm{~cm}$ 时最终萌发率仅为 $35 \%$, 但萌发后 植株的平均高度与其他各组差异不大, 在持续淹水 $120 \mathrm{~cm}$

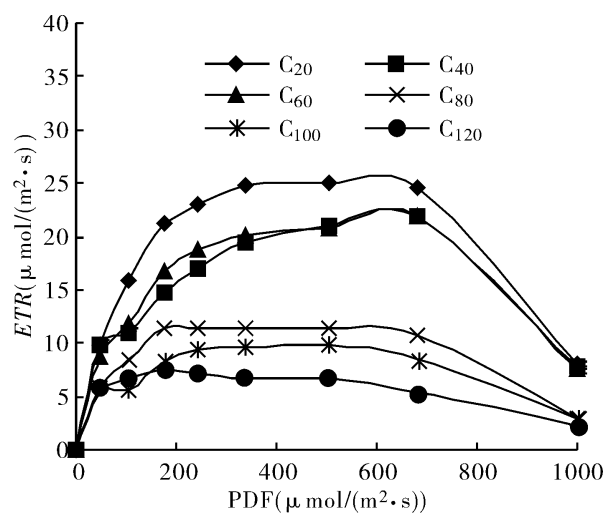

图 9 试验第 $86 \mathrm{~d}$ 各处理快速光响应曲线

Fig. 9 The rapid-light curves in each trcatment 86 days later 条件下, 菖蒲幼苗的萌发率约为淹水 $20 \mathrm{~cm}$ 条件下的 $1 / 3$, 但幼苗的平均高度为淹水 $20 \mathrm{~cm}$ 条件下的 $3 / 4$ 左 右. 菖蒲幼苗叶片长度、宽度和基茎直径随淹水深度增加而减小, 叶片面积也随淹水深度增加而减小, 其中 叶面积下降极为明显, 叶片宽度、数量与基茎减小明显. 在淹水条件下, 菖蒲幼苗的光合作用和呼吸作用受 到抑制, 各器官的生长发育都受到限制, 叶面积减小; 其次是细胞的增殖, 影响了叶片面积的增大, 进而造成 植物生物量的减少. 淹水导致叶绿素 $\mathrm{a} 、 \mathrm{~b}$ 和总叶绿素含量下降. 菖蒲幼苗在完全淹水 $(100-120 \mathrm{~cm})$ 条件 下, 虽然叶绿素含量下降, 但并没有影响到菖蒲幼苗的存活. 菖蒲幼苗在水深为 $100-120 \mathrm{~cm}$ 的逆境条件下 时, 叶片细胞膜脂过氧化加剧, 细胞质膜透性增加. 深水不仅限制光资源的获取, 而且也限制植物体内部氧 
气的运输, 而氧气浓度会制约营养吸收, 从而降低生长速率 ${ }^{[13]}$. 完全淹水明显影响到菖蒲幼苗的萌发生长 和生物量的积累.

试验发现, 长时间完全淹水 $(100-120 \mathrm{~cm})$ 对菖蒲幼苗光合系统 PS II 的有显著影响, 影响菖蒲幼苗 PS II 的非循环光合电子传递速率, 天线色素吸收的光能用于光化学电子传递的份额减少, 参与 $\mathrm{CO}_{2}$ 固定的电 子减少, 但在试验的 $86 \mathrm{~d}$, 菖蒲叶片 PS II 系统没有遭到破坏. 完全淹水对菖蒲植株的光响应曲线具有较大 的影响, 这种影响主要体现在随淹水深度的增加, 可利用光照强度减少对植株的影响加剧.

\section{4 参考文献}

[1] 王学雷,蔡述明,任宪友等.三峡库区消落带湿地生态建设与保护利用. 长江流域资源与环境,2004,13 (2) : $149-152$.

[2] Loucks W L. Flood tolerant tress. J For , 1987, 85: 36 - 40.

[3] Lenka V, Edita M, Olga V et al. Growth and biomass allocation of sweet flag (Acorus calamus L. ) under different nutrient conditions. Hydrobiologia, 2004, 518:9-22.

[4] Arnon D I. Copper Enzymes in isolated chloroplasts polyphenoloxidase in Beta vulgaris. Plant Physio, 1949, $24(1): 1-15$.

[5] 王韶唐编. 植物生理学实验指导. 西安:陕西科学技术出版社, 1987: $150-152$.

[6] 刘祖祺,张石城. 植物抗性生理学. 北京:中国农业出版社,1994:198-221.

[7] 米海莉, 许 兴,李树华等. 水分胁迫对牛心朴子、甘草叶片色素、可溶性糖、淀粉含量及碳氮比的影 响. 西北植物学报,2004,24(10). 1816 - 1821 .

[8] Fridovich I. Superoxide dismutase. Ann Rev Biochem, 1975, 44:147 - 159 .

[9] 惠红霞,许 兴, 李前荣. 外源甜菜碱对盐胁迫下枸杞光合功能的改善. 西北植物学报, 2003,23 (12) :2137 - 2422 .

[10] Genty B, Briantais J M, Baker N R. The relationship between the quantum yield of photosynthetic electron transport and quenching of chlorophyll fluorescence. Biochim Biophys Acta, 1989, 990 : 87 - 92.

[11] Schreiber U, Gademann R, Ralph P J et al. Assessment of photosynthetic performance of Prochloron in Lissoclinum patella in hospite by chlorophyll fluorescence measurements. Plant Cell Physiol, 1997,38( 8 ) : 945 -951 .

[12] Hook D D. Water logging tolerance of low land tree species of the south. Southern Journal of Applied Forestry, $1984,8: 136-149$.

[13] Koch M S, Mendelssohn I A, McKee K L. Mechanisms for the hydrogen sulfide-induced growth limitation in wetland macrophytes. Limnol Oceanogr, 1990, 35(2):399 - 408. 